\title{
Determinantes da Demanda de Crédito Rural por Pecuaristas de Corte no Estado de São Paulo ${ }^{1}$
}

\author{
Marcelo José Carrer², Hildo Meirelles de Souza Filho ${ }^{3}$ e \\ Marcela de Mello Brandão Vinholis ${ }^{4}$
}

Resumo: Este trabalho tem o objetivo principal de identificar os determinantes da demanda e do acesso ao crédito rural por bovinocultores de corte no estado de São Paulo. Para atingir tal objetivo, foram coletados dados primários por meio de entrevistas presenciais junto a uma amostra de 86 pecuaristas. Os dados foram analisados por meio de um modelo logit. Constatou-se que todos os pecuaristas que demandaram crédito rural obtiveram acesso a pelo menos um contrato. Os resultados mostraram que pecuaristas que têm maior número de propriedades rurais, maior intensidade em tecnologia na produção, fontes de renda oriunda de atividades não rurais, são mais novos, adotam gestão de risco de preço e participam de organizações associativas relacionadas à produção rural possuem maior probabilidade de demandar e acessar o crédito rural. Por fim, foram apresentadas algumas sugestões para a política de crédito rural para a pecuária de corte no estado de São Paulo.

Palavras-chaves: Crédito rural, pecuária de corte, demanda, logit.

\begin{abstract}
The aim of this paper is to identify determinants of demand and access to rural credit by beef cattle farmers in the São Paulo State. Primary data were collected from 86 beef cattle farmers through a questionnaire survey. The empirical analysis of the survey data is performed with the estimation of a logit model. The results show that all farmers who demanded credit in 2010 had access to it. The logit model results showed that farmers who own more farms are more intensive in production technology, receive non-farm activities income, are younger, adopt price risk management and are members
\end{abstract}

1 Os autores agradecem à Fapesp pelo apoio financeiro (projeto de auxílio regular de pesquisa 2010/02787-0).

2 Economista, mestre em Engenharia de Produção. Doutorando em Engenharia de Produção da UFSCar e professor dos cursos de Administração e Engenharia de Produção na Fundação Hermínio Ometto (FHO/Uniararas). E-mail: marcelojcarrer@dep.ufscar.br

3 Economista, PhD em Agricultural Economics. Professor do Departamento de Engenharia de Produção e do Programa de Pós-Graduação em Engenharia de Produção da UFSCar. E-mail: hildo@dep.ufscar.br

4 Engenheira agrônoma, doutora em Engenharia de Produção. Pesquisadora da Embrapa Pecuária Sudeste. E-mail: marcela.vinholis@embrapa.br 
of organizations related to rural production have higher probability to demand and access rural credit. Finally, some suggestions were presented for the rural credit policy for beef cattle in São Paulo State.

Key-words: Rural credit, beef cattle, demand, logit model.

Classificação JEL: Q12, Q18.

\section{Introdução}

Apesar de o Brasil ter sido o segundo maior produtor mundial de carne bovina e o maior exportador do produto em 2012, a pecuária de corte brasileira ainda é marcada por grande heterogeneidade. Coexistem diferentes sistemas de produção, nos quais são adotados diferentes padrões de tecnologia, gestão e comercialização. IEL, CNA e Sebrae (2000) identificaram a coexistência de dois sistemas distintos na cadeia de produção de carne bovina de corte brasileira: no Sistema A, encontram-se pecuaristas de alto nível tecnológico, que utilizam técnicas avançadas de produção animal; enquanto no Sistema B, estão pecuaristas menos intensivos em utilização de tecnologia. Zylbersztajn e Machado Filho (2003) também classificaram a pecuária de corte em dois subsistemas: i) subsistema de alta qualidade e ii) subsistema de baixa qualidade. Enquanto o primeiro subsistema é caracterizado pela adoção de tecnologias, por padrões eficientes de gestão e comercialização e, consequentemente, maior produtividade e qualidade no produto final, o segundo subsistema é caracterizado pela produção de forma extensiva e com pouca intensidade tecnológica e por padrões precários de gestão e comercialização do gado bovino.
No caso do estado de São Paulo, desde o final de década de 1990 notam-se pressões para uma maior intensificação em capital na pecuária de corte. Tal intensificação, por meio da adoção de tecnologias de produção e gestão, é capaz de promover ganhos de produtividade e qualidade, respondendo ao ambiente mais competitivo e aumentando a viabilidade econômica da atividade. Os principais fatores que pressionam os pecuaristas de corte paulistas a realizar investimentos em produtividade e qualidade são a elevação no preço das terras em São Paulo ${ }^{5}$, as demandas institucionais por sustentabilidade na produção rural e segurança do alimento e o surgimento de nichos de mercado que demandam maior qualidade e padronização na carne bovina. Enquanto alguns pecuaristas paulistas responderam a esse novo contexto adotando novas tecnologias de produção com consequentes ganhos de produtividade, outros pecuaristas continuam conduzindo a atividade de forma extensiva. Como resultado desta dualidade, o estado de São

\footnotetext{
5 Para acompanhar a evolução dos preços das terras nas principais microrregiões paulistas, ver IEA: <http://ciagri.iea. sp.gov.br/bancoiea/precor.aspx?cod_tipo $=1 \&$ cod_sis $=8>$.
} 
Paulo, tradicional fornecedor de gado bovino, vem perdendo sua participação no mercado 6 .

Diante do cenário observado, o crédito rural pode ser um importante instrumento para aproximar a pecuária de corte paulista àquilo que Zylbersztajn e Machado Filho (2003) classificaram como subsistema de alta qualidade. $\mathrm{O}$ acesso ao crédito reduz a limitação orçamentária dos produtores rurais e possibilita investimentos na produção e adoção de novas tecnologias com consequentes ganhos de produtividade e qualidade que podem estar associados à redução nos custos de produção. $\mathrm{O}$ acesso ao crédito pode, ainda, tornar projetos rurais viáveis, garantir a liquidez necessária para custear o processo produtivo e, consequentemente, aumentar a produção rural de alta qualidade (DIAGNE et al., 2000; BUAINAIN et al., 2007). Embora o acesso ao crédito seja uma importante alavanca, é necessário destacar que outros fatores impedem a difusão de inovações. Por exemplo, a pecuária extensiva de corte é capaz de produzir animais a baixo custo, que atendem à demanda de canais de comercialização que procuram por menor preço e pouco valorizam a qualidade da carne. Além disso, a pecuária de corte é uma atividade secundária para muitos pecuaristas, os quais conduzem a atividade de forma extensiva e com baixa intensidade em tecnologia. Daí a resistência do subsistema de baixa qualidade.

O crédito rural é o principal instrumento da política agrícola vigente no Brasil ${ }^{7}$. A oferta do crédito rural oficial no Brasil, apesar de limitada ${ }^{8}$, é feita com taxa de juros controlada pelo

6 Em 2010, os estados com maior número de cabeças de bovinos foram: Mato Grosso, Minas Gerais, Mato Grosso do Sul e Goiás (IBGE, 2011). São Paulo, que já esteve entre os estados com maior rebanho no Brasil, possuía apenas o 8o maior rebanho em 2010.

7 No Brasil, pode-se classificar a oferta de crédito rural em: i) crédito rural para produtores familiares (Pronaf) e, ii) crédito rural para produtores empresariais. No presente estudo, as análises compreendem a demanda e o acesso ao crédito rural por pecuaristas empresariais.

8 Durante a realização deste trabalho (dados referentes ao ano de 2010), os limites para obtenção das linhas oficiais de crédito de investimento e custeio eram, respectivamente, R\$ 200 mil e R\$ 275 mil. No entanto, no ano safra 2011/2012, governo, que, no ano safra 2010/2011 foi de 6,75\% ao ano para a linha de custeio e para as principais linhas de investimento disponíveis'. Essa taxa é mais baixa do que a taxa Selic - que, em 2010, oscilou entre $8,75 \%$ e $10,75 \%$ ao ano - e, se utilizado o IPCA de 2010 para calcular a taxa de juros real, obtém-se uma taxa de juros de 0,79\% ao ano. Existe, ainda, a oferta de crédito rural a taxas de juros livres feita pelas instituições financeiras e por agentes das cadeias de produção agroindustriais (trade credit) que, apesar de se apresentar mais alta do que os recursos controlados pelo governo, também se mostra como alternativa para o financiamento da produção rural. Entretanto, conforme Villa Verde (2000), a pecuária é uma atividade caracterizada tradicionalmente pela baixa utilização do crédito rural. Dados do IBGE (2006) confirmam essa característica da atividade. Em 2006, do total dos investimentos e despesas correntes dos bovinocultores no estado de São Paulo, apenas 9,59\% (R\$ 462,92 milhões) foram realizados com recursos do crédito rural oficial. Na agricultura, cerca de $20 \%$ das despesas correntes e dos investimentos feitos pelos produtores em 2006 foram financiados pelos recursos do crédito rural oficial.

Algumas hipóteses para a baixa utilização do crédito na pecuária de corte perpassam pela aversão ao risco dos pecuaristas, pela maior liquidez da atividade com relação a outras culturas agrícolas, pela maior disponibilidade de recursos financeiros oriundos de outras atividades econômicas dos pecuaristas, entre outras questões. Contudo, nenhuma hipótese foi submetida a testes empíricos. Para suprir essa lacuna, o presente artigo tem como principal objetivo identificar os determinantes da demanda e do acesso ao crédito rural por pecuaristas de corte no estado de São Paulo.

o governo federal aumentou esses limites para $\mathrm{R} \$ 300$ mil e R\$ 650 mil, respectivamente.

9 Apesar de a taxa de 6,75\% ao ano ser aquela que vigorava para a linha de custeio e para a maioria das linhas de investimento, é importante mencionar que existem alguns programas/linhas de investimento que apresentam taxas de juros diferentes. Por exemplo, o programa Agricultura de Baixo Carbono $(\mathrm{ABC})$, que visa principalmente à integração lavoura-pecuária-florestas, tem taxa de juros de 5,5\% ao ano. 
É importante ressaltar que todos os pecuaristas da amostra deste estudo que demandaram crédito rural, obtiveram acesso a pelo menos um contrato. Desta forma, a análise do acesso ao crédito rural está limitada àqueles que demandaram e foram atendidos e àqueles que não demandaram. Portanto, a análise não alcança aqueles que demandaram e não foram atendidos por limitação da amostra. A equivalência aqui encontrada entre demanda e acesso, apesar de apresentar um resultado interessante, é uma coincidência decorrente da amostra de pecuaristas utilizada ${ }^{10}$.

Esse artigo tem, ainda, o objetivo específico de identificar e discutir os fatores que levam os pecuaristas a não demandar crédito rural. Nesse caso, serão utilizados dados dos pecuaristas da amostra que não demandaram crédito. Para atingir tais objetivos, foram realizadas entrevistas pessoais in loco junto a 86 pecuaristas nas principais mesorregiões do estado de São Paulo no período de janeiro a agosto de 2011. Os dados serão analisados por meio de um modelo de escolha qualitativa (modelo logit). Esse modelo visa testar hipóteses a respeito de determinantes da demanda de crédito rural pelos pecuaristas. A demanda de crédito é uma variável que assume valores 0 ou 1 (variável binária), cuja análise econométrica é melhor realizada por meio de modelos de escolha qualitativa, como o modelo logit. Esses modelos não apresentam os problemas de estimação e inferência dos modelos tradicionais de regressão (MQO, por exemplo) para esse tipo de análise. Assim, modelos de escolha qualitativa apresentam resultados mais robustos e, em virtude disso, são preferíveis em relação a outros modelos (GREENE, 2003).

O estudo apresenta caráter inovador, visto que, apesar da importância de se entender o processo decisório de demanda e os determinantes

10 Demanda pode ser definida como sendo solicitação por recursos (crédito rural) que os pecuaristas fazem junto às instituições financeiras. A decisão de solicitar ou não o crédito é inerente ao pecuarista, ou seja, é um processo decisório do pecuarista. Já o acesso ao crédito rural depende das condições de avaliação (screening) e da oferta de crédito, que, em última instância, são determinadas pelas instituições financeiras. da demanda do crédito rural, não há registros de outros estudos que fizeram esse tipo de análise para a pecuária de corte no Brasil. A maioria dos outros estudos aplicados a esse setor e com essa mesma temática preocupou-se em analisar a oferta e a evolução da oferta de crédito para os pecuaristas. Por meio de um melhor entendimento das variáveis que afetam a demanda e dos principais motivos para a não demanda de crédito, o presente estudo tem grande potencial de contribuir para a formulação e melhoria de políticas públicas e estratégias privadas relacionadas ao crédito rural na pecuária de corte.

Após essa introdução, apresenta-se, de forma breve, uma aplicação da Nova Economia Institucional (NEI) no que tange ao funcionamento do mercado de crédito rural e os possíveis determinantes da demanda e do acesso ao crédito rural. Na seção três, é feita uma descrição da amostra seguida pela apresentação do modelo logit. Na seção quatro são apresentados e discutidos os resultados encontrados. Por fim, na seção cinco apresentam-se as conclusões, limitações e implicações para a formulação de políticas deste trabalho.

\section{Referencial teórico}

Hoff e Stiglitz (1993) e Besley (1994) analisaram o funcionamento dos mercados de crédito rural (mercado formal e mercado informal). Os autores constataram que a lógica de equilíbrio walrasiana não se aplica para os mercados de crédito. A taxa de juros não é exclusivamente um mecanismo de equilíbrio entre oferta e demanda e, em algumas situações de excesso de demanda, pode existir racionamento de crédito por parte dos credores sem necessariamente ocorrer aumento na taxa de juros. O principal motivo para tal é a existência de informação assimétrica entre os credores e mutuários. Em outras palavras, os credores não têm condições de conhecer, pelo menos a um custo razoável, todas as informações relevantes acerca dos mutuários e da aplicação dos recursos emprestados, tanto antes como após a realiza- 
ção dos empréstimos. Como consequência, são necessários mecanismos de avaliação (screening) e monitoramento (monitoring) devido às possíveis falhas ao se "fazer cumprir" (enforcement) cláusulas dos contratos de crédito. As duas situações descritas anteriormente, antes e após a realização dos empréstimos, são conhecidas na literatura da Nova Economia Institucional (NEI) como seleção adversa e risco moral. A seleção adversa afeta os agentes antes de a transação ocorrer (ex ante). Ela pode ser caracterizada como uma situação na qual os credores não podem, pelo menos a um custo razoável, distinguir entre os bons e os maus pagadores, o que torna necessário o desenvolvimento de mecanismos de avaliação (screening). Além da necessidade de fazer uma boa avaliação dos mutuários, os credores, em algumas situações, precisam exigir colaterais nos empréstimos para minimizar a probabilidade de ocorrer seleção adversa. $\mathrm{O}$ risco moral afeta os agentes depois de ocorridas as transações (ex post), e se caracteriza como uma situação na qual o tomador de crédito faz uso de informações em benefício próprio após o contrato ser lavrado. Por exemplo, o tomador de crédito pode desviar os recursos para outros propósitos, o que pode aumentar consideravelmente o risco da operação. Para resolver o problema do risco moral, os credores precisam utilizar mecanismos para monitorar a aplicação dos recursos emprestados (HOFF e STIGLITZ, 1993; BESLEY, 1994; BUAINAIN et al., 2007). Diante deste cenário de assimetria de informações, os agentes ofertadores de crédito podem racionar crédito em algumas situações, oferecendo crédito apenas para aqueles clientes de mais baixo risco, ou ainda, dificultando o acesso ao crédito por clientes de maior risco. Da mesma forma, alguns produtores rurais podem obter mais informação do que outros acerca da oferta e dos processos necessários para a obtenção de crédito rural.

Com base nesse enfoque da informação assimétrica, Hoff e Stiglitz (1993) e Besley (1994) identificaram os três principais problemas que permeiam as transações de crédito rural: i) problema de avaliação dos mutuários (screening); ii) problema de incentivos e monitoramento e iii) problema de "fazer cumprir" os contratos (enforcement). A resposta dos agentes a esses três problemas diferencia o mercado de crédito rural de um mercado com concorrência perfeita, no qual o preço equilibra oferta e demanda ${ }^{11}$; explica a coexistência de credores formais e informais e as diferentes taxas de juros cobradas por eles; explica a segmentação do mercado entre diferentes regiões; explica a inter-relação entre o mercado de crédito e o mercado de produtos; entre outras importantes questões que afetam os custos de transação, a eficiência alocativa e o desempenho dos mercados de crédito rural (HOFF e STIGLITZ, 1993; BESLEY, 1994).

No Brasil, há recursos para o crédito rural com taxa de juros nominal controlada de 6,75\% ao ano, o que torna bastante razoável supor que o problema de utilização de crédito não está simplesmente relacionado com a taxa de juros, mas com critérios de avaliação (screening) dos produtores pelos agentes ofertadores de crédito, de demanda de crédito pelos produtores rurais, de limites na obtenção dos empréstimos e de custos de transação. Há ainda a questão da baixa eficiência do sistema judiciário para fazer valer os direitos dos credores em casos de inadimplência (DJANKOV et al. 2005; ALMEIDA e ZYLBERSZTAJN, 2008). Essa situação reforça ainda mais a necessidade de uma boa avaliação (screening) dos tomadores de crédito e de fortes mecanismos de incentivo na utilização do crédito para reduzir a probabilidade de inadimplência devido à má aplicação dos recursos (risco moral).

Neste contexto, tornam-se importantes estudos que visam encontrar as variáveis que expliquem a demanda, o acesso e, consequentemente, a utilização de crédito por produtores rurais. Antes de iniciar a exposição dos determinantes da demanda e acesso ao crédito rural, cabe destacar que, no Brasil, as linhas de crédito ofertadas para

\footnotetext{
11 No caso do mercado de crédito rural, a taxa de juros não atua exclusivamente como mecanismo de equilíbrio entre oferta e demanda. Taxas de juros muito elevadas podem aumentar consideravelmente o risco de uma carteira de empréstimos e provocar seleção adversa, o que indica que, além de mecanismo de preço propriamente dito, a taxa de juros também é um mecanismo de screening.
} 
os produtores rurais podem ser divididas entre crédito para produtores rurais empresariais, cujo planejamento da política é feito pelo Ministério da Agricultura, Pecuária e Abastecimento (Mapa); e crédito para produtores rurais familiares (Pronaf), cujo planejamento da política é feito pelo Ministério do Desenvolvimento Agrário (MDA). Conforme já mencionado na introdução, as análises desse estudo estão relacionadas à demanda e acesso ao crédito rural por pecuaristas empresariais. Neste sentido, existe uma única linha de custeio e diferentes linhas/programas de investimento direcionadas a esse público ${ }^{12}$.

A seguir, serão apresentadas algumas variáveis que podem explicar a demanda, o acesso e a utilização de crédito rural pelos produtores rurais. As variáveis foram levantadas com base em estudos teóricos e empíricos já realizados acerca do tema. Com base nessas variáveis, serão construídas hipóteses que posteriormente serão testadas por meio de um modelo econométrico.

\subsection{Fatores determinantes da demanda, do acesso e da utilização de crédito rural}

\subsubsection{Fontes de renda oriundas de outras atividades}

Um dos grandes problemas para as instituições financeiras que operam com o crédito rural é o risco associado às especificidades da agropecuária (BUAINAIN et al., 2007) ${ }^{13}$. O seguro da produção agropecuária poderia minimizar esse risco;

12 Destacam-se, além da linha de investimento tradicional, linhas de investimento incluídas em programas mais amplos, como por exemplo: ABC, Produsa, Pronamp, Moderagro, Moderinfra e Moderfrota. Devido às limitações de espaço e pelo fato de o objetivo do trabalho ser analisar questões relacionadas à demanda, e não à oferta de crédito rural, não é possível apresentar e discutir as características de cada uma das linhas de crédito rural disponíveis no Brasil. Para o leitor interessado, ver o Plano Agrícola e Pecuário, disponível no site do Ministério da Agricultura Pecuária e Abastecimento <www.agricultura.gov.br $>$.

13 Essas especificidades estão relacionadas ao longo período de tempo existente entre investimentos e receitas na atividade agropecuária, à sazonalidade da produção e dos preços agropecuários, ao risco climático existente nas atividades agropecuárias, entre outras características que diferenciam o setor agropecuário de outros setores da economia. contudo, o Brasil ainda carece de um mercado de seguro rural desenvolvido (OZAKI, 2008).

Estudo da FAO (1998) mostra que muitas experiências de crédito rural em países em desenvolvimento apresentaram resultados negativos porque as instituições financeiras concentraram-se exclusivamente no crédito rural, ampliando os riscos e os custos de suas carteiras. Dessa forma, as instituições financeiras tendem a adotar medidas que minimizem o risco de suas carteiras. Uma dessas formas é conceder empréstimos a produtores com menor probabilidade de inadimplência. Esse é o caso de produtores rurais que possuem outras fontes de renda, além da renda oriunda da atividade rural. Em caso de quebra de safra, por exemplo, por fatores climáticos, esses produtores podem utilizar os recursos de outras fontes de renda para quitar os empréstimos rurais, não ficando exclusivamente dependentes da receita das atividades rurais. A renda de atividades não rurais pode ser considerada também uma forma de hedge para os produtores rurais.

Por outro lado, esses produtores tendem a ser os que menos precisam de crédito para financiar a produção devido ao fato de conseguirem utilizar recursos próprios para essa finalidade. Cria-se, portanto, um trade-off entre o objetivo da política governamental de atender ao público necessitado e as condições seguras de operação da política. Em estudo no Malauí, Diagne e Zeller (2001) verificaram que, quanto mais diversificada a composição da renda dos produtores rurais, maior a probabilidade destes em acessar crédito rural de fontes governamentais. Os autores concluíram que esses produtores apresentam risco reduzido para as instituições financeiras que operam com crédito rural. Shete e Garcia (2011) também constataram que ter atividades fora da propriedade rural aumenta a probabilidade do acesso ao crédito por produtores rurais da Etiópia. No presente estudo, parte-se da hipótese de que produtores que têm outras fontes de renda possuem maior probabilidade de demandar e acessar crédito rural.

Hipótese 1: Produtores rurais com outras fontes de renda possuem maior probabilidade de demandar e acessar crédito. 


\subsubsection{Número de propriedades}

Diversos autores mencionam que o acesso ao crédito rural está fortemente relacionado a fatores como o tamanho da propriedade e a capacidade do produtor em oferecer garantias ao credor (FEDER, 1993; JIMENEZ e SAURINA, 2003; ALMEIDA et al., 2010). Segundo Hoff e Stliglitz (1993), as garantias constituem-se em um dos principais dispositivos diretos utilizados pelos emprestadores quando não se tem perfeita informação sobre os tomadores de crédito. As garantias funcionam como um mecanismo de "fazer cumprir" (enforcement), pois criam desincentivos para a inadimplência. Estas possuem valor mais alto do que o valor dos empréstimos e, no caso de não cumprimento do contrato por motivo de inadimplência, são executadas pelos credores. Besley (1994) e Feder (1993) argumentam que, em situações caracterizadas pela assimetria de informações, os títulos de propriedade formais utilizados como colateral permitem que a oferta de crédito rural se expanda, reduzindo o seu racionamento.

No presente estudo, optou-se por utilizar o número de propriedades como uma proxy para a capacidade do produtor em oferecer garantias para o credor. A hipoteca da propriedade rural é a forma de garantia mais utilizada nos empréstimos de crédito rural no Brasil, o que reforça a ideia de que produtores com maior número de propriedades têm maior capacidade de oferecer garantias.

Barslund e Tarp (2008), em estudo sobre os determinantes da demanda e do racionamento de crédito rural no Vietnã, utilizaram uma variável dummy que buscou captar se o produtor possuía terra registrada em cartório (red book). A variável apresentou sinal positivo no modelo estimado pelos autores. No caso do presente estudo, a realidade é um pouco diferente daquela predominante no estudo citado, visto que todos os pecuaristas da amostra possuem pelo menos um título registrado de propriedade rural. Assim, será utilizado o número de escrituras de propriedades rurais que o produtor possui. Parte-se do pressuposto de que produtores rurais com maior número de propriedades têm vantagens na oferta de garantias e maior probabilidade de demandar e acessar crédito.

Hipótese 2: Quanto maior o número de propriedades rurais, maior a capacidade do produtor em ofertar garantias e, consequentemente, maior a probabilidade de demandar e acessar crédito rural.

\subsubsection{Intensidade em tecnologia na produção rural}

Mudanças tecnológicas na produção rural tendem a influenciar a oferta de recursos financeiros. Produtores rurais que estão em áreas caracterizadas pela adoção de novas tecnologias possuem vantagens no acesso ao crédito rural (IQBAL, 1988). Hoff e Stiglitz (1993) argumentam que novas tecnologias aumentam a produtividade e, consequentemente, a receita dos produtores, reduzindo o risco de inadimplência. Vale destacar que, no curto prazo, a adoção de novas tecnologias pode aumentar os custos de produção, não se refletindo imediatamente em maior rentabilidade líquida. Contudo, com o passar do tempo, a tendência é de ganhos na produtividade, redução nos custos médios e marginais e aumentos na receita líquida.

Segundo Barslund e Tarp (2008), a adoção de novas tecnologias pode estar direta e positivamente relacionada com a demanda por crédito, visto que o crédito é bastante importante para viabilizar economicamente a adoção destas. Além disso, sistemas de produção mais intensivos em tecnologia demandam maiores volumes de recursos financeiros para funcionarem em sua capacidade operacional ótima. Alguns autores encontraram evidências empíricas de que a demanda por insumos variáveis (fertilizantes, sementes, pesticidas, herbicidas, óleo diesel etc.) está direta e positivamente relacionada com a demanda por crédito rural (FEDER, 1993; DIAGNE e ZELLER, 2001). A própria concepção do crédito rural torna bastante plausível relacioná-lo com a aquisição de insumos. Sistemas 
de produção tecnologicamente mais intensivos demandam também maior volume de insumos produtivos fixos, o que tende a aumentar a demanda de recursos para investimento.

Em estudo com produtores rurais indianos, Kochar (1997) constatou que aqueles com maior área de terras irrigadas, portanto, tecnologicamente mais intensivos, têm maior probabilidade de demandar crédito rural. No presente estudo, será utilizada a engorda de animais no sistema de confinamento como uma proxy para medir a intensidade em tecnologia no sistema de produção dos pecuaristas. Justifica-se a escolha da engorda em confinamento com base em estudo da Embrapa (2005), o qual classifica o sistema de engorda em confinamento como sendo o mais intensivo em tecnologia na pecuária de corte brasileira.

Hipótese 3: Produtores com maior intensidade em tecnologia no sistema de produção possuem maior probabilidade de demandar e acessar crédito rural.

\subsubsection{Escolaridade do produtor}

Conforme Hoff e Stiglitz (1993), um dos principais problemas do mercado de crédito rural é a assimetria de informações entre credores e mutuários. Azevedo e Shikida (2004) encontraram evidências empíricas de que a assimetria de informações, de fato, afeta tanto os credores (risco moral e seleção adversa) como também os tomadores de crédito (falta de conhecimento sobre oferta de crédito etc.). Parece plausível admitir que um maior nível de instrução entre os produtores rurais pode aumentar a capacidade cognitiva destes e reduzir significativamente a assimetria de informações existente no mercado de crédito rural, aumentando o conhecimento destes produtores acerca da oferta de linhas de crédito e dos procedimentos necessários para a obtenção do crédito.

Por exemplo, no ano safra 2010/2011, a taxa de juros nominal vigente para a linha de custeio agropecuário foi de 6,75\% a.a. A taxa Selic neste mesmo período variou entre 10 e $12 \%$ a.a. Um produtor rural com recursos próprios disponíveis poderia investi-los na aquisição de títulos públicos (que remuneram a taxa Selic), tomar o montante equivalente em crédito rural para investir ou custear a produção e se aproveitar do spread entre as duas taxas. Mesmo com a inclusão dos custos de transação ${ }^{14}$, que tendem a elevar as taxas do crédito rural e reduzir a remuneração dos títulos públicos, parece plausível afirmar que pode existir ganho líquido oriundo do diferencial de taxas de juros. Pode-se argumentar que, conforme os pressupostos da NEI, os agentes têm racionalidade limitada e não conseguem identificar todas as alternativas possíveis para a alocação dos seus recursos financeiros. Isto de fato ocorre; contudo, parece mais uma vez plausível admitir que a possibilidade de fazer essa engenharia financeira está mais disponível para aqueles que têm nível de instrução mais elevado e que, apesar de possuírem racionalidade limitada, têm maior capacidade cognitiva.

Hipótese 4: Produtores rurais com mais anos de estudo possuem maior probabilidade de demandar e acessar crédito rural.

\subsubsection{Idade do produtor}

Braslund e Tarp (2008) utilizaram a variável idade do produtor como um dos possíveis determinantes da demanda de crédito por produtores rurais no Vietnã. A variável apresentou sinal negativo no modelo estimado pelos autores, o que significa que, quanto maior a idade dos produtores rurais daquele país, menor a probabilidade des-

\footnotetext{
14 Os principais custos das transações de crédito rural para o produtor são: os custos com o registro das garantias em cartório, os custos de negociação entre produtor e instituição financeira (custos de oportunidade do tempo perdido, despesas com telefone, despesas com idas e vindas ao banco etc.), os custos de elaboração e avaliação dos projetos, os custos de seguros e capitalizações quando esses são exigidos, entre outros. Já os custos de transação para a aquisição de títulos públicos são: taxa da CBLC (que, em janeiro de 2012, estava em torno de $0,3 \%$ do valor da transação), taxa do agente de custódia (que varia de acordo com o agente, sendo que a taxa do Banco do Brasil é de $0,5 \%$ do valor da transação) e o imposto de renda, que apesar de não ser propriamente um custo de transação, também reduz a remuneração líquida dos títulos.
} 
tes em demandar crédito. Os autores explicam que produtores mais velhos são mais conservadores, têm maior aversão ao risco e menor propensão a tomar iniciativas que demandem maior volume de capital. Os trabalhos de Shete e Garcia (2011) e Falkowski (2012) encontraram resultado semelhante.

De acordo com Villa Verde (2000), a pecuária de corte no Brasil é uma atividade tradicionalmente caracterizada pela baixa demanda por crédito rural e pelo financiamento com recursos próprios dos produtores. Uma das possíveis explicações para tal se dá na aversão ao risco pelos pecuaristas mais tradicionais. Espera-se que os produtores mais velhos tenham menor probabilidade de demandar crédito rural.

Hipótese 5: Quanto maior a idade do produtor, menor a probabilidade de demandar e acessar crédito rural.

\subsubsection{Gestão de risco de variação nos preços}

Em última instância, a viabilidade de um projeto agropecuário pode ser determinada pelo preço do produto agropecuário no momento de sua venda. É sabido que os preços dos produtos agropecuários apresentam grande volatilidade, o que pode comprometer a receita do produtor e sua capacidade de saldar os empréstimos contraídos. O risco associado aos preços aumenta a probabilidade de inadimplência e, consequentemente, o risco para as instituições financeiras que operam com o crédito rural. Segundo Azevedo e Shikida (2004), uma das principais causas de inadimplência nos empréstimos rurais mencionada pelas instituições financeiras que fizeram parte da amostra daquele estudo é a queda no preço do produto agropecuário financiado.

Alguns mecanismos foram desenvolvidos para minimizar o risco de variações nos preços agropecuários, dentre os quais encontram-se os contratos a termo com preço prefixado e os contratos em mercados futuros; ambos são os mais utilizados por produtores rurais no Brasil. Para os produtores, esses contratos possibilitam um planejamento financeiro mais preciso e seguro, garantindo antecipadamente o preço a ser recebido na venda do produto rural (hedge de preços). Para os emprestadores, o hedge de preços reduz o risco de inadimplência, à medida que os mutuários dos empréstimos (produtores rurais) não terão variações acentuadas na receita da produção.

Dessa forma, o gerenciamento dos riscos de variação de preços agropecuários pode ser considerado um mecanismo de incentivo para a utilização de crédito rural (LAZZARINI e CHADAD, 2000; BUAINAIN et al., 2007), aumentando a probabilidade de pagamento por parte do tomador e reduzindo o risco de inadimplência para o emprestador.

Hipótese 6: Produtores que utilizam algum mecanismo de hedge, como contratos a termo, futuros ou de opções, possuem maior probabilidade de demandar e acessar o crédito rural.

\subsubsection{Assistência técnica}

A assistência técnica é tida como importante ferramenta de transferência tecnológica; além do seu caráter fiscalizador, por meio da emissão de laudos de visitas ao banco financiador. Portanto, este instrumento é de grande funcionalidade na tentativa de redução do risco moral e da seleção adversa (AZEVEDO e SHIKIDA, 2004). A assistência técnica pode ser considerada um mecanismo de incentivo para a utilização do crédito rural, tanto por reduzir os riscos para as instituições financeiras como também por aumentar a probabilidade da adoção de novas tecnologias de produção e de ganhos de produtividade, os quais podem ser impulsionados e/ou possibilitados com a utilização do crédito rural. Azevedo e Shikida (2004), em estudo sobre a assimetria de informações entre ofertadores de crédito rural e produtores rurais cooperados da Coamo-PR, constaram que os agentes emprestadores costumam exigir o acompanhamento técnico da produção rural para liberar os empréstimos.

Hipótese 7: Produtores rurais que recebem assistência técnica têm maior probabilidade de demandar e acessar crédito rural. 
Tabela 1. Resultado esperado para as variáveis determinantes da demanda e do acesso ao crédito rural por produtores rurais

\begin{tabular}{cccc}
\hline Variável & Estudos empíricos que utilizaram a variável & $\begin{array}{c}\text { Sinal } \\
\text { esperado }\end{array}$ \\
\hline Renda de outras atividades & Diagne e Zeller (2001); Shete e Garcia (2011) & + \\
Número de propriedades & Field e Torero (2006); Barslund e Tarp (2008); Almeida et al. (2010); Shete e Garcia (2011)* & + \\
Intensidade em tecnologia & Kochar (1997); Diagne e Zeller (2001) & + \\
Escolaridade do produtor & Diagne e Zeller (2001); Barslund e Tarp (2008); Shete e Garcia (2011); Falkowski (2012) & + \\
Idade do produtor & Diagne e Zeller (2001); Barslund e Tarp (2008); Shete e Garcia (2011); Falkowski (2011) & - \\
Gestão de riscos & Falkowski (2012)** & + \\
Assistência técnica & Azevedo e Shikida (2004) & \\
Associativismo & & + \\
\hline
\end{tabular}

* Esses autores não utilizaram a variável número de propriedades, mas outras variáveis que também servem de proxy para a capacidade dos produtores em oferecer colaterais nos empréstimos rurais.

** O autor utilizou uma variável que visa captar se o produtor comercializa o produto rural em canais de distribuição mais modernos e que pagam preços melhores, reduzindo, assim, o risco associado à volatilidade de preços.

Fonte: Elaboração própria.

\subsubsection{Associativismo}

Adicionalmente à educação formal, participar de organizações associativas aumenta o conhecimento dos produtores rurais, bem como o acesso e o compartilhamento de importantes informações (BARON, 2007). As organizações associativas podem ser formais, como por exemplo, sindicatos rurais, cooperativas de produtores rurais e associações de classe, e também informais, como por exemplo, pool de compra de insumos e/ou de venda do produto rural. Essas associações, por aumentarem o acesso e o compartilhamento de informações entre os produtores, têm o potencial de reduzir a falta de conhecimento destes sobre a oferta de linhas de crédito rural e sobre os procedimentos necessários para a obtenção do crédito rural. A participação em organizações associativas tem, ainda, o potencial de aumentar o grau de conectividade do produtor com outros produtores e com outros agentes da cadeia agroindustrial e até mesmo formar uma rede política ${ }^{15}$.

15 Define-se rede política como um conjunto de instituições que se baseiam em regras acordadas para chegar a um objetivo comum, ou seja, institucionalizando um mecanismo de coordenação horizontal e reduzindo, assim, os custos de informação e transação, criando confiança e reduzindo incertezas (BÖRZEL, 1997).
A participação de produtores rurais em organizações associativas tem sido utilizada como uma proxy para capital social em alguns estudos empíricos sobre a adoção de tecnologias no Brasil e em outros países (BURTON et al., 1998; SILVA e MORAES, 2010). Alguns destes estudos constataram que produtores rurais que participam de organizações associativas têm maior probabilidade de adotar novas tecnologias. A adoção de novas tecnologias, por sua vez, pode ser facilitada pelo crédito rural, aumentando a demanda dos produtores rurais pelo crédito. Logo, pode-se pressupor que produtores rurais que participam de organizações associativas, além de possuírem maior acesso à informação sobre a oferta e procedimentos necessários para a obtenção de crédito rural, também têm maior probabilidade de demandar e acessar crédito rural para adotar novas tecnologias.

Hipótese 8: A participação dos produtores rurais em organizações associativas aumenta a probabilidade destes em demandar e acessar crédito rural.

A Tabela 1 apresenta as variáveis que serão analisadas no presente estudo e os resultados esperados para cada uma delas com base no referencial teórico apresentado nesta subseção. 


\section{Metodologia}

Esse estudo seguiu a metodologia proposta por Diagne et al. (2000) para estudar questões relacionadas à demanda e acesso ao crédito por produtores rurais. Na próxima subseção será descrita a amostra utilizada. Após a descrição da amostra, será apresentado o modelo econométrico adotado para proceder o teste das hipóteses levantadas.

\subsection{Amostra}

Os dados utilizados no presente estudo foram obtidos a partir da aplicação de um questionário estruturado junto a uma amostra não probabilística de 86 pecuaristas de corte no estado de São Paulo (Tabela 2). Estes pecuaristas detinham 189 propriedades rurais localizadas no estado (Tabela 3). As entrevistas foram presenciais e realizadas pelos autores do trabalho, sendo executadas no período de janeiro a setembro de 2011. Os dados coletados referem-se ao ano de 2010. Cabe mencionar que os dados foram obtidos no âmbito de um projeto de pesquisa que objetivou analisar diversas questões relacionadas à pecuária de corte em São Paulo. Diante da grande dificuldade para a obtenção de dados primários neste setor, da restrição orçamentária presente em pesquisas de campo e da inexistência de uma lista com os nomes de todos os pecuaristas de corte do estado de São Paulo, obteve-se uma amostra não probabilística, o que se constitui em uma limitação deste trabalho. Para solucionar o problema da inexistência de um cadastro de pecuaristas, foram obtidas listas junto a sindicatos rurais, a associações de bovinocultores de corte e a empresas ligadas ao agronegócio (empresas de consultoria, empresas que comercializam insumos e agroindústrias processadoras) nas principais regiões produtoras do estado de São Paulo. A partir dessas listas, foram contatados, aleatoriamente, pecuaristas para as entrevistas, obtendo-se uma amostra formada por 86 pecuaristas. Foram entrevistados pecuaristas que se localizavam em 10 mesorregiões do estado de São Paulo. Obteve-se uma amos-

Tabela 2. Distribuição geográfica da amostra de pecuaristas de corte utilizada no presente estudo

\begin{tabular}{ccc}
\hline Mesorregião & Pecuaristas & $\%$ do total \\
\hline Araçatuba & 19 & 22,09 \\
Bauru & 13 & 15,12 \\
Marília & 5 & 5,81 \\
Presidente Prudente & 17 & 19,77 \\
Ribeirão Preto & 14 & 16,28 \\
São José do Rio Preto & 13 & 15,12 \\
Outras & 5 & 5,81 \\
Total & 86 & 100 \\
\hline
\end{tabular}

Fonte: Dados da pesquisa.

Tabela 3. Número de propriedades da amostra e do estado São Paulo, classificadas por intervalo de número de cabeças de bovinos

\begin{tabular}{ccccc}
\hline $\mathbf{N}^{\circ}$ de cabeças & № de propriedades (IBGE, 2006) & $\%$ & No de propriedades amostra & \% \\
\hline De 50 a 99 & 8985 & 35,0 & 39 & 37 \\
De 100 a 199 & 7395 & 28,8 & 49 & 19,6 \\
De 200 a 499 & 5978 & 23,3 & 64 & 25,9 \\
Mais de 500 & 3280 & 12,8 & 189 & 33,9 \\
Total & 25638 & 100 & 100 \\
\hline
\end{tabular}

* Foram consideradas apenas as propriedades com 50 ou mais cabeças de bovinos.

Fonte: IBGE (2006) e dados da pesquisa. 
tra que compreendeu pecuaristas que adotavam diversos sistemas de produção (confinamentos, semiconfinamentos, pasto extensivo etc.), diversos mecanismos de comercialização (mercado spot, mercados futuros, contratos a termo etc.) e com diferentes características socioeconômicas. Adicionalmente, foram realizadas: duas entrevistas semiestruturadas junto aos gerentes de agronegócio do Banco do Brasil nas mesorregiões de Araçatuba e Bauru; e uma entrevista semiestruturada junto ao gerente de operações de mercado de um grande frigorífico que fornece crédito para bovinocultores por meio de Cédula de Produto Rural (CPR) e adiantamento de contrato a termo.

\subsection{Modelos de escolha qualitativa}

Para identificar os fatores que determinam a demanda de crédito rural por pecuaristas de corte no estado de São Paulo, será utilizado um modelo de regressão com a variável dependente (ou explicada) qualitativa binária, que assume os valores 0 ou 1 .

Os modelos de escolha qualitativa são bastante utilizados para explicar a probabilidade de um indivíduo ou um conjunto de indivíduos tomarem uma decisão, ou de um determinado evento ocorrer. Nesse caso, a escolha do indivíduo em tomar ou não determinada decisão, ou a probabilidade de o evento ocorrer ou não, é baseada em uma série de fatores explicativos e pode tomar a forma da seguinte função (GREENE, 2003):

$\operatorname{Prob}($ evento $j$ ocorrer $)=\operatorname{Prob}(Y=j)=$
$=f[$ fatores relevantes, parâmetros]

Aparentemente, poder-se-ia aplicar a lógica de estimação dos modelos de regressão linear para os modelos de escolha qualitativa, visto que a ideia destes modelos é encontrar a melhor combinação de variáveis independentes que explicam a probabilidade de determinado evento ocorrer. Contudo, há uma série de problemas de estimação e inferência que surgem na utilização do modelo clássico de regressão linear (MQO) para estimar modelos de escolha qualitativa. Desta forma, é necessária a utilização de outras aborda- gens metodológicas para uma apropriada especificação, estimação e uso de modelos de escolha qualitativa. A seguir apresentam-se dois modelos bastante utilizados, os modelos logit e probit.

\subsubsection{Modelos logit e probit}

Nos modelos logit/probit, a variável a ser explicada é de escolha qualitativa: demandar crédito rural/não demandar crédito rural.

Ao tomar a decisão de demandar ou não demandar crédito rural, pode-se pressupor que o produtor considera as vantagens e desvantagens marginais de utilizar crédito para investir ou custear a produção. Como os parâmetros dessa decisão não são geralmente observáveis, para cada propriedade rural $i$, pode ser definida uma variável latente, $y^{*}$, como

$$
y_{i}^{*}=\beta^{\prime} X_{i}+u_{i} i=1, \ldots, N
$$

em que $X$ denota um conjunto de variáveis explicativas. O padrão observado de demanda por crédito rural pode ser descrito por uma variável dummy, $y$, tal que $y i=1$ se o produtor $i$ demanda crédito rural, $y i=0$ se esse produtor não demanda crédito rural. Esses valores observados de y são relacionados com $y^{*}$ da seguinte forma:

$$
\begin{aligned}
& y i=1 \text { se } y i *>0 \\
& \text { yi }=0 \text { caso contrário }
\end{aligned}
$$

e

$$
\begin{aligned}
& \operatorname{Pr}\left(y_{i}=1\right)=\operatorname{Pr}\left(y_{i}^{*}>0\right)=\operatorname{Pr}\left(u_{i}>-\beta^{\prime} X_{i}\right)= \\
& =1-F\left(-\beta^{\prime} X_{i}\right)=F\left(\beta^{\prime} X_{i}\right)
\end{aligned}
$$

em que Fé uma função de distribuição cumulativa para $u$ e uma distribuição simétrica é assumida.

Assim, as estimativas dos parâmetros $\beta$ podem ser obtidas utilizando-se procedimentos de máxima verossimilhança.

No modelo probit, uma distribuição normal é escolhida para $F\left(\beta^{\prime} X\right)$; para o modelo logit, uma função de distribuição cumulativa logística é assumida. Como os modelos apresentam resultados muito semelhantes, pode-se escolher qualquer um dos dois. Neste trabalho, optou-se pelo modelo logit por sua maior simplicidade matemática. No modelo logit, 
Tabela 4. Variáveis a serem utilizadas no modelo logit

\begin{tabular}{|c|c|}
\hline Variável & Descrição \\
\hline \multicolumn{2}{|l|}{ Variável dependente } \\
\hline Demanda de crédito rural em 2010 (DEMAND) & $\begin{array}{l}\text { Variável dummy de valor igual a } 1 \text { na ocorrência de demanda* e } 0 \text { caso } \\
\text { contrário. }\end{array}$ \\
\hline \multicolumn{2}{|l|}{ Variáveis explicativas } \\
\hline Idade $(I D A D E)$ & Idade do pecuarista. \\
\hline Escolaridade (ESTUDO) & Anos de estudo formal do pecuarista. \\
\hline Participação em organizações associativas (ASS) & $\begin{array}{l}\text { Variável dummy de valor igual a } 1 \text { se participa de organizações associa- } \\
\text { tivas e } 0 \text { caso contrário. }\end{array}$ \\
\hline Renda em outras atividades não rurais (ROT) & $\begin{array}{l}\text { Variável dummy de valor igual a } 1 \text { se possui outras rendas além da ati- } \\
\text { vidade rural e } 0 \text { caso contrário. }\end{array}$ \\
\hline $\begin{array}{l}\text { Adoção de mecanismos de gestão de risco de preço } \\
(G E S T)\end{array}$ & $\begin{array}{l}\text { Variável dummy de valor igual a } 1 \text { se adota contrato a termo e/ou con- } \\
\text { tratos futuros e/ou de opções e } 0 \text { caso contrário. }\end{array}$ \\
\hline Assistência técnica e/ou consultoria (ASSIST) & $\begin{array}{l}\text { Variável dummy de valor igual a } 1 \text { se recebe assistência e/ou consultoria } \\
\text { e } 0 \text { caso contrário. }\end{array}$ \\
\hline Grau de intensidade em tecnologia (KTEC) & $\begin{array}{l}\text { Variável dummy de valor igual a } 1 \text { se adota o confinamento como siste- } \\
\text { ma de produção e } 0 \text { caso contrário. }\end{array}$ \\
\hline $\begin{array}{l}\text { Número de propriedades rurais legalmente registradas } \\
\text { (NPROPS) }\end{array}$ & $\begin{array}{l}\text { Número de propriedades com registro em cartório que o pecuarista } \\
\text { possui. }\end{array}$ \\
\hline
\end{tabular}

* Como demanda e acesso estão associados neste estudo, a ocorrência de demanda também implicará na ocorrência de acesso ao crédito.

Fonte: Elaboração própria.

$$
\begin{aligned}
\operatorname{Pr}\left(y_{i}=1\right)=\frac{e^{\beta x}}{1+e^{\beta x}} \\
=\Lambda(\beta X)
\end{aligned}
$$

em que $\Lambda$ denota a função de distribuição cumulativa logística.

Os fatores determinantes da demanda de crédito rural por bovinocultores de corte em São Paulo podem ser divididos em três categorias: características do produtor, características da propriedade e características mercadológicas (Tabela 4). Na apresentação dos resultados do modelo, serão utilizados os 'odds ratio' (ou $e^{\beta}$ ), além dos coeficientes $\beta$ propriamente ditos.

\section{Análise dos resultados}

Os resultados do presente estudo estão divididos em duas subseções. A primeira subseção apresenta uma análise qualitativa de fatores explicativos para a não demanda de crédito rural por 33 bovinocultores de corte da amostra. Na segunda subseção são apresentados e discutidos os resul- tados do modelo logit utilizado para identificar os fatores que determinam a demanda de crédito rural pelos bovinocultores de corte da amostra.

\subsection{Fatores explicativos para a não demanda de crédito rural por bovinocultores de corte}

Como o principal objetivo deste estudo é identificar os determinantes da demanda e do acesso ao crédito rural pelos pecuaristas de corte, a amostra foi subdividida entre os pecuaristas que demandaram crédito para a atividade pecuária em 2010 e aqueles que não demandaram crédito. Foi questionado aos pecuaristas se eles solicitaram empréstimos para financiar a produção pecuária em 2010. Para os pecuaristas que responderam sim, perguntou-se, adicionalmente, se os pedidos de empréstimos foram aceitos, bem como foram realizadas questões relacionadas aos contratos de crédito obtidos.

Dentre os 86 pecuaristas, 53 deles $(62 \%$ da amostra) demandaram crédito rural. Os demais, 
Tabela 5. Principais razões para não demandar crédito rural, 33 pecuaristas, possibilidade de resposta múltipla

\begin{tabular}{lcc}
\hline & Frequência de respostas & $\begin{array}{c}\text { \% de pecuaristas } \\
\text { que responderam }\end{array}$ \\
\hline Filosofia de trabalho & 5 & 15,15 \\
Receio de perder as garantias exigidas & 15 & 45,45 \\
Oferta insuficiente & 3 & 9,09 \\
Problemas com dívidas anteriores & 0 & 0,00 \\
Burocracia/custos de transação & 20 & 60,60 \\
Prazo para pagamento insuficiente & 0 & 0,00 \\
Taxa de juros elevada & 3 & 9,09 \\
Instabilidade do mercado de boi gordo & 3 & 9,09 \\
Falta de informações sobre oferta de crédito para pecuária & 4 & 12,12 \\
Alta liquidez da atividade pecuária & 12 & 36,36
\end{tabular}

Fonte: Resultados da pesquisa.

33 pecuaristas, não demandaram crédito rural em 2010. Conforme mencionado na Seção 1, todos os pecuaristas que declararam demandar crédito rural em 2010 conseguiram obter pelo menos um empréstimo. Logo, a demanda e o acesso ao crédito estão associados neste estudo. Essa situação mostra que não há um cenário de racionamento intensivo de crédito rural para os pecuaristas que fizeram parte da amostra deste trabalho ${ }^{16}$. Na verdade, o racionamento de crédito rural oficial é definido pelo limite máximo de recursos por produtor, caracterizando-se mais como um racionamento extensivo de crédito. Contudo, para contornar os limites máximos de obtenção de recursos oficiais, os pecuaristas podem adotar estratégias que combinem a utilização de recursos controlados do crédito rural oficial com a utilização de recursos a taxas de juros determinadas pelo mercado.

Para os pecuaristas que não demandaram crédito rural em 2010, foi questionado o motivo para tal. A Tabela 5 apresenta a frequência e o percen-

16 O racionamento intensivo de crédito ocorre quando a política de crédito define um grupo-objetivo de poucos produtores rurais para os quais são concedidos grandes volumes de crédito em detrimento de um grande número de produtores que não possuem acesso ao crédito. $\mathrm{O}$ racionamento extensivo de crédito ocorre quando a política de crédito se preocupa em assegurar crédito ao maior número possível de produtores rurais, o que, dados os limites orçamentários da política, implica no fracionamento dos recursos e na concessão de recursos em quantias menores para muitos produtores (BUAINAIN, 2000). tual de respostas para as principais razões citadas pelos pecuaristas.

A burocracia existente no processo de obtenção do crédito rural foi citada por $60,6 \%$ dos pecuaristas que não demandaram crédito em 2010, tendo sido o motivo mais citado. A burocracia aumenta consideravelmente os custos de transação relacionados à obrigatoriedade da compra de outros serviços financeiros (títulos de capitalização, seguros, poupança etc.), aos deslocamentos até a agência bancária, à elaboração do projeto de investimento quando necessário, ao registro das garantias em cartório, ao prazo para liberação dos empréstimos, entre outros. A depender do valor financiado, os custos de transação podem ser bastante representativos, inviabilizando a operação. Do ponto de vista das instituições financeiras, custos médios de transação são reduzidos quanto um grande volume financeiro é operado por meio de poucos contratos. Neste caso, os custos de transação, como por exemplo, o tempo e os recursos despendidos para avaliar o cadastro e o projeto do pecuarista, para negociar as garantias e cláusulas contratuais, bem como para monitorar a aplicação dos recursos, são diluídos.

Cabe destacar que, apesar de as exigências impostas pelas instituições financeiras afastarem alguns pecuaristas da demanda pelo crédito rural, não é tão simples afrouxar as regras para análise e concessão do crédito sem correr o risco de aumentar a inadimplência. No entanto, há 
de se mencionar a diferença entre as regras para análise e concessão do crédito rural (política de crédito da instituição financeira) e a burocracia associada a essa concessão. $\mathrm{O}$ afrouxamento das regras para análise e concessão, conforme já mencionado, não é desejável. Por sua vez, a redução da burocracia que está associada à exigência de documentos muitas vezes desnecessários, à necessidade de contratação de outros serviços financeiros e à lentidão na análise e liberação dos recursos é bastante desejável, desde que não afete a eficácia das garantias e o risco para os bancos.

O segundo motivo mais citado pelos pecuaristas que não demandaram crédito rural foi o receio de perder as garantias exigidas na transação. Dos 33 pecuaristas que não demandaram crédito, 15 apontaram o receio de perder as garantias como um dos principais motivos. Esses pecuaristas afirmaram que a garantia exigida é sempre a propriedade rural, que possui um valor muito mais alto do que o valor do empréstimo. $\mathrm{Na}$ visão das instituições financeiras, o valor é necessário para cobrir o empréstimo e os encargos de inadimplência computados durante o tempo necessário para a solução definitiva do processo judicial, o qual pode demorar anos. Assim, o problema também está relacionado à morosidade do sistema judiciário brasileiro e às regras atualmente vigentes relacionadas à condução do processo judicial, as quais aumentam consideravelmente os custos de transação para as instituições financeiras. As próprias incertezas inerentes à atividade e à capacidade de gerar saldos financeiros para pagar os empréstimos levam esses pecuaristas a não demandarem crédito, visto que, em caso de inadimplência, o pecuarista pode perder seu patrimônio. Este parece ser um mecanismo de autoexclusão de projetos ruins. Em outras palavras, os pecuaristas, por não terem certeza de que seus projetos gerarão rendimentos suficientes para quitar os empréstimos, e diante da exigência de colaterais na obtenção do crédito, não demandam crédito rural.

A alta liquidez da atividade pecuária foi mencionada por 12 dos 33 pecuaristas que não demandaram crédito rural. Esses pecuaristas con- sideram a possibilidade de vender o gado para fazer caixa quando necessário como uma alternativa ao financiamento da produção. Essa característica diferencia a pecuária da agricultura, onde os ciclos são mais rígidos e tornam a liquidez da atividade menor, e pode explicar porque tradicionalmente a pecuária de corte é caracterizada pela baixa utilização de crédito rural. Entretanto, conforme será apresentado na próxima subseção, o processo de intensificação tecnológica da atividade pecuária reduz consideravelmente a liquidez da atividade e a possibilidade de utilizar o gado como reserva de valor que pode ser vendida para custear a produção quando necessário.

Alguns pecuaristas $(15,15 \%)$ afirmaram que não demandam e não utilizam crédito devido à filosofia de não trabalhar alavancado com recursos de terceiros. Neste caso, os pecuaristas simplesmente alegaram que preferem utilizar os recursos próprios para financiar a atividade, sem maiores explicações. A falta de informações sobre a oferta de recursos para a pecuária de corte foi citada como motivo para não demandar crédito por quatro pecuaristas. Nestes casos de falta de informações sobre a oferta de crédito rural, constatou-se que a assimetria de informações no mercado de crédito rural também afeta os mutuários, conforme mencionado por Azevedo e Shikida (2004).

Os motivos "taxa de juros elevada" e "instabilidade do mercado de boi gordo" estão correlacionados. Todos os pecuaristas que citaram o primeiro motivo também citaram o segundo motivo. Na verdade, o problema neste caso não é a taxa de juros propriamente dita, mas, sim, as variações acentuadas no preço do boi gordo, que podem comprometer consideravelmente a rentabilidade da atividade pecuária. Em períodos com preços muito baixos, a rentabilidade da atividade para alguns pecuaristas pode ficar abaixo dos $6,75 \%$ (taxa de juros dos recursos controlados para custeio e investimento), comprometendo a capacidade destes em saldar os empréstimos. Aqui, cabe sugerir um maior planejamento financeiro e do processo de comercialização pelos pecuaristas. Dentre os mecanismos que podem 
Tabela 6. Resultados do modelo logit - fatores determinantes da demanda de crédito rural por bovinocultores de corte

\begin{tabular}{|c|c|c|c|c|}
\hline & Coeficientes $\left(\beta_{\mathrm{k}}\right)$ & Odds ratio $\left(\mathrm{e}^{\beta \kappa}\right)$ & Erro padrão & Value-p \\
\hline NPROPS* & 0,5517 & 1,7362 & 0,2526 & 0,029 \\
\hline $\mathrm{IDADE}^{* *}$ & $-0,0474$ & 0,9537 & 0,0246 & 0,053 \\
\hline ESTUDO & 0,0829 & 1,0864 & 0,1142 & 0,468 \\
\hline KTEC* & 0,5943 & 1,8118 & 0,2884 & 0,029 \\
\hline $\mathrm{ROT}^{* *}$ & 0,5181 & 1,6788 & 0,3035 & 0,087 \\
\hline ASSIST & $-0,1194$ & 0,8875 & 0,2929 & 0,683 \\
\hline $\mathrm{ASS}^{* *}$ & 0,5428 & 1,7208 & 0,3178 & 0,088 \\
\hline CONSTANTE & 0,0482 & - & 2,2246 & 0,982 \\
\hline Log-Likelihood & & $-41,4397$ & & \\
\hline Restr. $(\beta s=0)$ Log-L & & $-57,2636$ & & \\
\hline chi2 (7) & & 31,65 & & \\
\hline \multicolumn{5}{|l|}{$\mathrm{N}=86$} \\
\hline Estimativas corretas, demanda & & $84,90 \%$ & & \\
\hline Estimativas corretas, não demanda & & $66,66 \%$ & & \\
\hline Pseudo Nagelkerke R2 & & 0,4183 & & \\
\hline
\end{tabular}

* Significativo ao nível de 5\%.

** Significativo ao nível de $10 \%$.

Fonte: Resultados da pesquisa.

ser adotados para tal, estão os contratos a termo e os contratos futuros, os quais podem minimizar o risco da variação nos preços e o impacto dessa variação na rentabilidade da atividade, considerados, obviamente, seus custos operacionais.

Três pecuaristas afirmaram que não demandaram crédito em 2010 devido à baixa oferta de recursos. Nestes casos, ao contrário dos casos de falta de informação, os pecuaristas até possuem conhecimento sobre a oferta de recursos; contudo, devido aos limites na obtenção de recursos controlados pelo governo, esses pecuaristas não demandaram crédito. Neste caso, ambos são grandes pecuaristas que não conseguiriam suprir sua demanda por recursos com os limites de $\mathrm{R} \$ 275.000,00$ para o custeio da atividade e de $\mathrm{R} \$ 200.000,00$ para o investimento tradicional. É importante lembrar que o limite para custeio subiu, no ano safra 2012/2013, dos R\$275.000,00 para $\mathrm{R} \$ 650.000,00$ e que, além dos recursos do investimento tradicional, há linhas de recursos do BNDES destinadas ao investimento da atividade pecuária. Há ainda recursos a taxas de juros livres e recursos disponibilizados pelos agentes da cadeia de produção (trade credit) para financiar a atividade. Logo, o motivo baixa oferta de recursos não condiz com a realidade e aponta para outros determinantes da não demanda de crédito rural por esses pecuaristas.

Os motivos "problemas com dívidas anteriores" e "prazo para pagamento insuficiente" não foram citados pelos pecuaristas da amostra.

Pelo exposto, pode-se concluir que a taxa de juros por si só não é um mecanismo de autoexclusão dos pecuaristas na demanda por crédito rural. Contudo, a taxa de juros adicionada dos custos de transação (motivo burocracia) e da autoavaliação do risco de perda da garantia são motivos que explicam a autosseleção e, consequentemente, a autoexclusão de alguns pecuaristas da demanda e do acesso ao crédito rural.

\subsection{Fatores determinantes da demanda de crédito rural por bovinocultores de corte}

A Tabela 6 apresenta os resultados do modelo logit. ${ }^{17} \mathrm{O}$ teste de razão de máxima verossimi-

\footnotetext{
17 As análises foram procedidas utilizando-se o programa Statistica 10.0.
} 
lhança (likelihood ratio test) foi utilizado para testar a hipótese de que todos os parâmetros $(\beta \mathrm{s})$ da regressão são iguais a 0 . O qui quadrado, calculado a partir do log likelihood restricted (sem a inclusão dos parâmetros) e do log likelihood unrestricted (com a inclusão dos parâmetros), apresentou o valor de 31,65. Com 7 graus de liberdade, o valor crítico do qui quadrado tabelado ao nível de $5 \%$ de significância é de 20,28. Logo, a hipótese de que todos os coeficientes do modelo são iguais a 0 pode ser rejeitada, o que permite utilizar o modelo para explicar os determinantes da demanda por crédito rural por pecuaristas de corte paulistas. Dentre os pecuaristas que demandaram crédito em 2010, $84,90 \%$ foram previstos corretamente pelo modelo. Dentre os que não demandaram crédito, $66,66 \%$ foram previstos de forma correta pelo modelo.

Os resultados dos parâmetros estimados no modelo estão de acordo com a teoria proposta para estudar a demanda por crédito rural. $\mathrm{O}$ único parâmetro que não apresentou o sinal esperado foi o parâmetro da variável ASSIST. No entanto, ele não se mostrou estatisticamente significativo aos níveis de $5 \%$ ou $10 \%$. Com exceção das variáveis ESTUDO e ASSIST, todas as outras variáveis do modelo são estatisticamente significativas aos níveis de $5 \%$ ou $10 \%$ de significância. Desta forma, não se rejeitam as hipóteses levantadas no referencial teórico, com exceção das de número 4 e 7 . A variável GEST foi excluída do modelo devido ao seu alto grau de correlação com a variável KTEC o que, por sua vez, pode causar o problema de multicolinearidade no modelo ${ }^{18}$. Contudo, essa variável é importante para explicar a demanda de crédito rural pelos pecuaristas da amostra. A importância da variável GEST está no fato de que a variável com a qual ela tem alto grau de correlação (KTEC) apresentou um impacto positivo e estatisticamente significativo ao nível de $5 \%$ na demanda por crédito rural. Além disso, observou-se que $45,3 \%$ dos pecuaristas que demandaram crédito rural adotam mecanismos de gestão do risco de variação dos preços, à medida que apenas $21,2 \%$ dos que não deman-

18 A matriz de correlação das variáveis encontra-se no Anexo A. daram crédito adotam tais mecanismos. Apesar disso, optou-se por utilizar a variável KTEC, em detrimento da variável GEST, para comparar os resultados aqui obtidos com aqueles encontrados em outros estudos que utilizaram essa variável e devido à grande importância da adoção de tecnologia, assumida na literatura do crédito rural.

A interpretação dos odds ratio $\left(\mathrm{e}^{\beta}\right)$ pode ser feita por meio da fórmula $\left[\left(e^{\beta}-1\right)^{*} 100\right]$, que já apresenta a variação em pontos percentuais na probabilidade da variável dependente ser igual a 1 (pecuarista demandar crédito), como resposta à alteração de uma unidade na variável independente.

A variável que apresentou o coeficiente de maior valor foi a KTEC. Adotar o sistema de confinamento na engorda do gado aumenta em 81,18 pontos percentuais a probabilidade de o pecuarista demandar crédito rural, ceteris paribus. A principal explicação para esse impacto positivo da variável é que a engorda em confinamento demanda recursos consideráveis em alimentação, manejo do gado e até mesmo na gestão da propriedade, aumentando bastante os custos de operação do sistema produtivo. Além disso, a engorda em confinamento reduz a liquidez da atividade em relação ao sistema de pasto extensivo. No sistema de confinamento é utilizado maior volume de capital fixo e deixa-se de utilizar os animais como uma reserva de valor que pode ser vendida para fazer caixa quando necessário. Deste fato, explica-se também a correlação desta variável com a variável GEST, visto que, no sistema de confinamento, os pecuaristas precisam adotar mecanismos eficientes para a comercialização dos animais e para protegerem-se de variações acentuadas nos preços. O resultado para a variável KTEC no presente estudo está de acordo com os autores que relacionam positivamente a demanda por crédito com a adoção de novas tecnologias nos sistemas de produção agropecuários (IQBAL, 1988; BARSLUND e TARP, 2008; SHETE e GARCIA, 2011). Está também de acordo com a própria concepção da política agrícola brasileira dos anos 60 e 70, que se utilizou do crédito rural subsidiado como principal instrumento para promover a modernização das cadeias agroindustriais. 
A variável ROT também apresentou relação positiva com a probabilidade da demanda de crédito rural pelos pecuaristas de corte da amostra. Possuir fontes de renda de atividades não rurais aumenta em 67,88 pontos percentuais a probabilidade de o pecuarista demandar crédito rural, tudo o mais mantido constante. Esse resultado confirma a hipótese de que produtores rurais com outras fontes de renda são vistos pelas instituições que operam com o crédito rural como clientes de mais baixo risco. Logo, quando o processo de avaliação (screening) feito pelas instituições financeiras é capaz de identificar essa informação, esses pecuaristas podem obter vantagens no acesso ao crédito. As instituições financeiras podem, em alguns casos, reduzir os custos de transação e a exigência de garantias para esses pecuaristas. Durante a pesquisa de campo, foram identificados, inclusive, alguns casos nos quais as instituições financeiras procuravam os pecuaristas com outras fontes de renda para ofertar o crédito rural oficial e, assim, cumprir as metas dos empréstimos rurais e reduzir o risco de seus portfólios. Essas facilidades na obtenção dos empréstimos tendem, por sua vez, a criar/aumentar a demanda por crédito dos pecuaristas com outras fontes de renda e a afastar aqueles que não têm outras fontes de renda da demanda por crédito rural. O resultado da variável ROT está de acordo com os estudos de Diagne e Zeller (2001) e Shete e Garcia (2011). Do ponto de vista da política agrícola, esse resultado apresenta uma distorção. Os recursos controlados do crédito rural podem estar chegando às mãos dos produtores rurais que teriam condições de financiar a atividade com recursos próprios, em detrimento daqueles produtores que mais necessitam do crédito para financiar a produção.

Outra variável que apresentou relação positiva com a demanda por crédito rural foi a variável NPROPS. Conforme mencionado na subseção 2.1, essa variável foi utilizada como uma proxy da capacidade do pecuarista em oferecer garantias para os credores. Cada propriedade rural registrada legalmente aumenta em 73,62 pontos percentuais sua probabilidade em demandar crédito rural, tudo o mais mantido constante. Foi constatado na pesquisa de campo que alguns pecuaristas têm a estratégia de dividir a propriedade em várias propriedades de menor porte com diferentes escrituras. Como os bancos têm grande restrição em acolher garantias em graus subsequentes

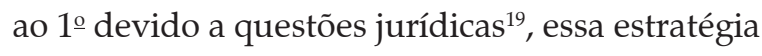
aumenta a capacidade do pecuarista em oferecer colaterais em diferentes empréstimos. Todavia, essa estratégia tem um custo que está relacionado, porém não limitado, a despesas cartorárias. O pecuarista pode, por exemplo, oferecer uma propriedade como colateral nos empréstimos do crédito oficial controlado pelo governo e ainda obter recursos adicionais de outras fontes de empréstimos, como, por exemplo, Cédulas de Produto Rural ${ }^{20}$, oferecendo outras propriedades como colateral. Além disso, ao dividir uma grande fazenda em várias fazendas menores com diferentes escrituras, o pecuarista pode oferecer garantias de valor mais próximo ao exigido pelas instituições financeiras, sem que se configure excesso, o que significaria, em caso de inadimplência, a perda de apenas parte de seu patrimônio. O resultado dessa variável confirma a importância das garantias nos empréstimos envolvendo crédito rural e está de acordo com vários estudos sobre o tema (FEDER, 1993; FIELD e TORERO, 2006; BARSLUND e TARP, 2008; ALMEIDA et al., 2010). Cabe aqui destacar a necessidade de um mercado de seguro rural bem desenvolvido no Brasil e, mais especificamente,

\footnotetext{
19 Geralmente, é preciso esperar a execução da primeira dívida se resolver (dívida em que a instituição financeira possui a hipoteca de 1o grau), para ter andamento na segunda, o que, associado à morosidade do judiciário, aumenta consideravelmente os custos de transação e os riscos em aceitar garantias de $2^{\circ}$ ou $3^{\circ}$ grau para as instituições financeiras.

20 A utilização de Cédulas de Produto Rural (CPRs) vem crescendo na pecuária de corte paulista, principalmente entre os produtores de maior porte e com maior número de propriedades. Esse mecanismo de financiamento apresenta algumas vantagens; contudo, uma das principais barreiras à sua maior difusão é que não são aceitas garantias registradas em outros empréstimos (garantias em graus subsequentes) para os contratos de CPR e, uma vez registrada no contrato de $\mathrm{CPR}$, a propriedade não pode ser ofertada como colateral em outros empréstimos.
} 
no estado de São Paulo. Besley (1994) afirma que a ausência de um mercado de seguro rural bem desenvolvido para mitigar as incertezas relativas à receita da produção rural é um dos principais problemas que afetam a eficiência do mercado de crédito rural dos países em desenvolvimento. No Brasil, ainda não foi desenvolvido um mercado eficiente de seguro rural. $\mathrm{O}$ desenvolvimento desse mercado poderia minimizar a exigência de garantias de alto valor, sem necessariamente aumentar o risco de inadimplência, aproximando produtores rurais de menor porte e com menor número de propriedades rurais da demanda, do acesso e da utilização do crédito rural.

A variável ASS se mostrou positivamente relacionada com a demanda de crédito rural dos pecuaristas de corte paulistas e estatisticamente significativa ao nível de $10 \%$ de significância. Participar de organizações associativas relacionadas com a produção rural aumenta em 72,08 pontos percentuais a probabilidade de o pecuarista demandar crédito rural, ceteris paribus. Esse impacto positivo da variável ASS apresenta evidências empíricas de que participar de organizações associativas aumenta o acesso e o compartilhamento de informações que podem ser importantes para os pecuaristas demandarem crédito e acessarem a política de crédito rural. Produtores rurais que participam de organizações associativas têm maior grau de conectividade com outros produtores e também com outros agentes da cadeia agroindustrial, o que pode facilitar o acesso à informação e também gerar externalidades positivas para o produtor, como por exemplo, facilidades no processo de obtenção do crédito rural. Além disso, é assumido na literatura que essa variável aumenta a probabilidade de produtores rurais adotarem novas tecnologias. A adoção de novas tecnologias, por sua vez, está positivamente relacionada com a demanda de crédito rural, conforme o resultado encontrado para a variável KTEC no presente estudo.

A variável IDADE é a única do modelo que apresentou relação negativa e estatisticamente significante com a demanda de crédito rural.
Conforme era esperado, quanto maior a idade do pecuarista, menor a probabilidade de demandar crédito. Esse resultado está de acordo com os estudos de Diagne (1999), Barslund e Tarp (2008) e Shete e Garcia (2011). A principal explicação para esse resultado é que os pecuaristas mais velhos têm maior aversão ao risco e são menos propensos a iniciativas que demandam montantes maiores de capital.

\section{Conclusões}

Este estudo visou explicar os determinantes da demanda e do acesso ao crédito rural por bovinocultores de corte em São Paulo. Percebeu-se que a demanda e o acesso ao crédito rural estavam associados. Ou seja, todos os pecuaristas da amostra deste estudo que demandaram crédito rural em 2010 obtiveram acesso. Esse primeiro resultado encontrado está de acordo com os estudos de Kochar (1997) e Barslund e Tarp (2008). O primeiro estudo citado reforça a importância de separar demanda de crédito de acesso ao crédito e assume que, muitas vezes, os produtores rurais não têm acesso ao crédito simplesmente por não demandarem recursos. O estudo supracitado foi feito na Índia e concluiu que o racionamento ao crédito rural daquele país é bem menor do que costuma ser assumido na literatura devido ao fato de que muitos dos produtores rurais que se presumia não obterem acesso ao crédito, simplesmente não demandaram crédito. Barslund e Tarp (2008) também optaram por separar a demanda de crédito do acesso ao crédito rural no Vietnam. Estes autores chegaram ao resultado de que a maioria dos produtores rurais que não obtiveram acesso ao crédito naquele país não demandaram empréstimos. No presente estudo, constatou-se que os pecuaristas da amostra que não acessaram crédito simplesmente não demandaram recursos.

Diante das razões encontradas para a não demanda por crédito rural, seria natural sugerir que as instituições financeiras facilitassem o acesso ao crédito rural para os pecuaristas, afrouxando as regras de análise do crédito e a exigên- 
cia de garantias de alto valor. Contudo, o presente estudo não segue esse caminho, visto que diversas experiências mostraram que o afrouxamento nas regras de análise do crédito rural pode levar a um cenário de alta inadimplência e, no longo prazo, à própria insustentabilidade financeira da política de crédito rural. Os próprios resultados do modelo econométrico podem e devem servir de input para sugerir medidas no âmbito da política de crédito rural. As sugestões que serão feitas a seguir não se limitam apenas ao escopo do mercado de crédito rural. Pelo contrário, tais sugestões perpassam por outros mercados e podem trazer como externalidade positiva uma maior demanda e acesso ao crédito rural pelos pecuaristas. Especificamente, sugere-se:

1. Maior estímulo à adoção de mecanismos de gestão de riscos pelos pecuaristas. Esses mecanismos podem ser tanto no âmbito da gestão do risco de variação de preços como também no âmbito da gestão do risco de intempéries climáticas e de perdas na produção rural. No último caso, o mecanismo adequado seria o seguro da produção rural, o qual ainda não tem um mercado bem desenvolvido no estado de São Paulo. Daí, concluí-se que este seria um mercado para intervenção do governo. O melhor desenvolvimento do mercado de seguro rural e a maior adoção de mecanismos de gestão de riscos pelos pecuaristas podem trazer como externalidade positiva a redução do risco de inadimplência e a possibilidade de as instituições financeiras reduzirem a exigência de garantias de alto valor. Neste cenário, seria possível reduzir a burocracia e a exigência de garantias de alto valor sem necessariamente aumentar o risco das operações de crédito rural.

2. Melhoria nos métodos de screening das instituições financeiras. A ideia aqui é que as instituições financeiras deixem de avaliar apenas o pecuarista, como ocorre muitas vezes, e passem a avaliar melhor o projeto apresentado e a projeção de viabilidade do mesmo. Neste caso, pecuaristas que não atendem aos requisitos que as instituições financeiras procuram, mas com bons projetos de financiamento, obteriam acesso ao crédito sem necessariamente arcar com altos custos de transação.

Esse estudo inovou ao identificar fatores explicativos para a não demanda e os determinantes da demanda de crédito rural por bovinocultores de corte. Não foram encontrados estudos de caráter semelhante na literatura relacionada a essa atividade produtiva, apesar da importância do tema. Todos os anos, o governo federal disponibiliza grandes montantes de recursos para os produtores rurais brasileiros sob a forma de crédito rural, sendo de fundamental importância identificar os fatores que determinam a demanda e o acesso a estes recursos. Com base nas variáveis encontradas no modelo econométrico e em outras constatações empíricas, foi possível sugerir medidas que podem aumentar a eficiência e a eficácia da política de crédito rural no Brasil, principal instrumento da política agrícola brasileira. Além disso, ficou constatada a importância do crédito rural para a adoção de tecnologia na pecuária de corte. No modelo econométrico estimado, a variável intensidade em tecnologia no sistema de produção (medida pela engorda em confinamento) apresentou sinal positivo e significância estatística. Logo, a maior utilização do crédito rural pelos pecuaristas pode reduzir a heterogeneidade existente na atividade, aumentando os níveis de produtividade, qualidade e, consequentemente, de competitividade.

Como principal limitação do estudo, deve-se mencionar o fato de a amostra ser não probabilística. No entanto, os dados foram obtidos de forma presencial pelos autores do trabalho, o que aproxima os pesquisadores do objeto de pesquisa e possibilita a obtenção de algumas informações que muito provavelmente não seriam obtidas de outras formas. A não inclusão de uma variável que buscasse captar o relacionamento do pecuarista com as instituições financeiras ou, 
mais especificamente, com os gerentes de agronegócio das instituições financeiras pode ser considerada outra limitação para o estudo. Barslund e Tarp (2008) utilizaram uma variável que buscou captar se os produtores rurais do Vietnã possuíam alguma relação de parentesco ou amizade com os gerentes das instituições financeiras. Foi constatado que essa variável impacta forte e positivamente a demanda e o acesso ao crédito rural pelos produtores daquele país.

Para estudos futuros, abre-se o tema de analisar o impacto da utilização do crédito rural nos indicadores de eficiência produtiva da pecuária de corte. Macedo (2006), com base em dados secundários, verificou que há indícios de relação positiva entre o crescimento da oferta de crédito rural e a modernização da pecuária de corte no Brasil. No entanto, não há registro de estudos de caráter microanalítico que avaliem o impacto da utilização de crédito rural nos indicadores de eficiência produtiva e competitividade de cada pecuarista, com base em dados primários e métodos consistentes de estimação. Outro tema interessante seria a comparação dos resultados aqui encontrados para os pecuaristas de corte em São Paulo com pecuaristas de outros estados, ou mesmo com produtores de outras atividades agropecuárias no estado de São Paulo. A comparação pode servir para verificar se há um padrão entre os produtores rurais que se beneficiam da política de crédito rural no Brasil, ou se os fatores determinantes da demanda e do acesso ao crédito rural variam de acordo com a atividade produtiva e/ou com o estado em que os produtores se encontram inseridos.

\section{Referências bibliográficas}

ALMEIDA, L.F. e ZYLBERSZTAJN, D. Crédito Agrícola no Brasil: uma perspectiva institucional sobre a evolução dos contratos. Internext (São Paulo), v. 3, p. 267-287, 2008.

ALMEIDA, L.F., ZYLBERSZTAJN, D. e KLEIN, P.G. Determinants of contractual arrangements in agricultural credit transactions. Revista de Administração (FEA/USP), v. 45, n. 3, p. 209-220, 2010.
AZEVEDO, C.M. e SHIKIDA, F.A. Assimetria de informação e o crédito agropecuário: o caso dos cooperados da Coamo-Toledo (PR). Revista de Economia e Sociologia Rural, v. 42, n. 2, p. 267-292, 2004

BARON, R.A. Behavioral and cognitive factors in entrepreneurship: entrepreneurs as the active element in new venture creation. Strat. Entrepreneurship J., n. 1, p. 167-182, 2007.

BARSLUND, M. e TARP, F. Formal and informal rural credit in four provinces of Vietnam. Journal of Development Studies, v. 44, n. 4, p. 485-503, 2008.

BESLEY, T. How do market failures justify interventions in rural credit markets? The World Bank Research Observer, v. 9, n. 1, p. 27-47, 1994.

BÖRZEL, T. "Qué tienen de especial los policy networks? Explorando el concepto y su utilidad para el estudio de la gobernación europea", 1997. Disponível em: < http:// seneca.uab.es/antropologia/redes/redes.htm $>$.

BUAINAIN, A.M. (Org.). Manual de macroeconomia. Instituto de Economia - UNICAMP. 2000 (mimeo.).

BUAINAIN, A.M., GONZÁLES; M.G., SOUZA FILHO, H.M. e VIEIRA, A.C.P. Alternativas de financiamento agropecuário: experiências no Brasil e na América Latina. Brasília: IICA, 2007.

BURTON, M., YOUNG, T., SOUZA FILHO, H.M. e RIGBY, D. The Adoption of Sustainable Agricultural Technologies in Paraná, Brazil. Revista de Economia e Sociologia Rural, v. 36, n. 4, p. 199-222, 1998

DIAGNE, A., ZELLER, M. e SHARMA, M. Empirical measurement of households' access to credit and credit constraints in developing countries: Methodological issues and evidence. Food Consumption and Nutrition Division (FCND). Discussion Paper 90, IFPRI, Washington-USA, 2000.

DIAGNE, A. e ZELLER, M. Access to credit and its impact on welfare in Malawi. Research Report 116, International Food Policy Research Institute, Washington-USA, 153 p., 2001.

DJANKOV, S., MCLIESH, C. e SHLEIFER, A. Private Credit in 129 Countries. National Bureau of Economic Research. National Bureau of Economic Research Working Paper Series, 39 p., 2005. Disponível em http:// www.nber.org/papers/w11078

EMBRAPA. Sistemas de produção de gado de corte no Brasil: uma descrição com ênfase no regime alimentar e no abate. Documentos/EMBRAPA gado de corte. 40 p., 2005.

FALKOWSKI, J. Vertical coordination, access to capital, and producer loyalty in the Polish dairy sector. Agricultural Economics, v. 43, n. 2, p. 155-164, 2012. 
FAO (1998). ¿Se Justifica el Replanteamiento de las Finanzas Agrícolas? Serie Replanteamiento de Las Finanzas Agrícolas (AFR). no. 1. FAO - GTZ. Rome.

FEDER, G. The Economics of Land and Titling in Thailand. In: HOFF, K., BRAVERMAN, A. e STIGLITZ, J. (Eds.). The economics of rural organization: Theory, practice and policy. Oxford, University Press, Oxford, 1993.

FIELD, E. e TORERO, M. Do property titles increase credit access among the urban poor? Evidence from a Nationwide Titling Program. Princeton: Princeton University, 2006 (mimeo).

GREENE, W. Econometric analysis. 5 ed. New Jersey: Prentice Hal, 1026 p., 2003.

HOFF, K. e STIGLITZ, J. Imperfect information and rural credit markets: Puzzles and policy perspectives, In: HOFF, K.; BRAVERMAN, A. e STIGLITZ, J. (Eds.) The economics of rural organization: Theory, practice and policy. Oxford, University Press, Oxford, 1993.

IQBAL, F. The determinants of moneylender interest rates: evidence from rural India. Journal of Development Studies, v. 24, n. 3, p. 364-378, 1988.

INSTITUTO BRASILEIRO DE GEOGRAFIA E ESTATÍSTICA. Censo Agropecuário 2006. Disponível em <www.sidra.ibge.gov.br> Acesso em: 5 mar. 2011.

INSTITUTO BRASILEIRO DE GEOGRAFIA E ESTATÍSTICA. Pesquisa Pecuária Municipal. Disponível em <www.sidra.ibge.gov.br> Acesso em: 10 nov. 2011.

IEL; CNA; SEBRAE. Estudo sobre a eficiência econômica e competitiva da cadeia agroindustrial da pecuária de corte no Brasil. Brasília: 2000, 416p.

JIMENEZ, G. e SAURINA, J. Collateral, type of lender and relationship banking as determinants of credit risk. Journal of Banking and Finance, v. 28, n. 9, p. 21912212, 2004.

KOCHAR, A. An empirical investigation of rationing constraints in rural credit markets in India. Journal of Development Economics, v. 53, p. 339-371, 1997.

LAZZARINI, S.G. e CHADDAD, F.R. Finanças no agribusiness. In: ZYLBERSZTAJN, D. e NEVES, M.F. (Eds.). Gestão e economia dos negócios agroalimentares. São Paulo: Editora Pioneira, 2000.

MACEDO, L.O.B. Modernização da pecuária de corte bovina no Brasil e a importância do crédito rural. Informações Econômicas, v. 36, n. 7, p. 83-95, 2006.

MINISTÉRIO DA AGRICULTURA PECUÁRIA E ABASTECIMENTO. Plano Agrícola e Pecuário 2011/2012. Disponível em <www.agricultura.gov.br $>$.

OZAKI, V.A. Em busca de um novo paradigma para o seguro rural no Brasil. Revista de Economia e Sociologia Rural, v. 46, n. 1, p. 97-119, 2008.

SHETE, M. e GARCIA, R.J. Agricultural credit market participation in Finoteselam town, Ethiopia. Journal of Agribusiness in Developing and Emerging Economies, v. 1, n. 1, p. 55-74, 2011.

SILVA, C. B. e MORAES, M. A. F. D. Inovação na indústria sucroalcooleira paulista: os determinantes da adoção das tecnologias de agricultura de precisão. Revista de Economia e Sociologia Rural, v. 48, p. 543-565, 2010.

VILLA VERDE, C.M. O Crédito Rural e a Capacidade de Pagamento do Setor Agrícola. Instituto de Pesquisa Econômica Aplicada, Texto para Discussão No 696, 2000.

ZYLBERSZTAJN, D. e MACHADO FILHO, C.A.P. Competitiveness of meat agri-food chain in Brazil. Supply Chain Management: An International Journal, v. 8, n. 2, p. 155-165, 2003. 
Anexo A. Matriz de correlação das variáveis explicativas do modelo logit utilizado para explicar os determinantes da demanda de crédito rural pelos pecuaristas*

\begin{tabular}{lcccccccc}
\hline & ASS & ROT & IDADE & ESTUDO & GEST & NPROPS & KTEC & ASSIST \\
\hline ASS & 1,000 & 0,147 & 0,039 & 0,125 & 0,184 & 0,166 & 0,085 & 0,149 \\
ROT & 0,147 & 1,000 & $-0,097$ & 0,167 & 0,097 & $-0,013$ & 0,055 & 0,296 \\
IDADE & 0,039 & $-0,097$ & 1,000 & $-0,046$ & $-0,193$ & $-0,120$ & $-0,184$ & $-0,111$ \\
ESTUDO & 0,125 & 0,167 & $-0,046$ & 1,000 & 0,157 & 0,050 & 0,288 & 0,114 \\
GEST & 0,184 & 0,097 & $-0,193$ & 0,157 & 1,000 & 0,349 & 0,613 & 0,215 \\
NPROPS & 0,166 & $-0,013$ & $-0,120$ & 0,050 & 0,349 & 1,000 & 0,333 & 0,155 \\
KTEC & 0,085 & 0,055 & $-0,184$ & 0,288 & 0,613 & 0,333 & 1,000 & 0,097 \\
ASSIST & 0,149 & 0,296 & $-0,111$ & 0,114 & 0,215 & 0,155 & 0,097 & 1,000 \\
\hline
\end{tabular}

* Os valores em negrito são estatisticamente significativos ao nível de $5 \%$.

Fonte: Resultados da pesquisa. 